\title{
Development of the Kinematic Effectiveness of Negative Acceleration Phase of 100 Meter Sprinters
}

\author{
Hassan Ibrahim Abd El-Hamid Abou El-Magd', Mohammed Abd-elwahab Abd-elhady \\ Elbadry $^{2}$
}

${ }^{1}$ Lecturer at the Department of Track and Field Competition's Applications and Theories, Faculty of Physical Education for Boys, Zagazig University, Egypt

${ }^{2}$ Lecturer at the Department of Sport Training and Kinesiology, Faculty of Physical Education for Boys - Zagazig University, Egypt

\begin{abstract}
:
This study aims to develop the kinematic effectiveness of 100 meter run in general and especially reduce maximum acceleration phase through the kinematic analysis of the 100 meter run segments and the phase of reduced maximum acceleration of the segment (70 - 80 meter), and the effect of the proposed training program on the kinematic variables. The researchers used the experimental method based on biomechanical analysis by using (5) cameras of frequencies 30 cadres/second and Simi Motion program for movement analysis on a sample of (3) international players of the Egyptian National Team, and every player perform (2) trials, meaning that there was (6) trials as a whole. The results revealed the most important kinematic variables of 100 meter run segments in general and the phase of Negative acceleration phase of the segment (70-80 meter) the Negative acceleration phase was developed for the longest distance which was improved from (72 meter) to (74 meter), the researchers recommend the guidance of the kinematic markers of the study and to use the specific training (Helper - resistance) to improve the length and frequency of the stride.
\end{abstract}

\section{Introduction and research problem}

B iomechanics is an academic science determined to study the human movement, biomechanics deals with applications of the basis and mechanical rules on living bodies in motion and stillness and explain the causes of body changes and study the different techniques of sports skill ness and ways of its development (Talha, 2014: 17).

The sprints, especially the 100 meters, have traditionally been the blue rib and events of athletics, attracting the attention of sports fans and casual observers alike with any activity or fact related to the fastest man, or woman, in the world. In this respect, our sport is currently enjoying a golden age because of both the general high level of performance and especially the star power of Usain Bolt, who has redefined what is possible for a sprinter. (The International Association of Athletics Federations, 2011:3)

Tamazin and Coh (2005) and Frye (2000) state that the style of running for runners depends on the physical and morphological abilities which affect some mechanical sides of performance such as speed and stride length and its frequency. Stride length is controlled by the strength of the runner during the period of landing in the ground, and stride length improvement is not achieved by changing of style but by improvement of the power to produce strength which will help in improving the frequency of the stride, and the percent of the stride frequency and its length is individual state and work automatically that means that the mote the frequency, the less the stride length and vice versa, the maximum speed of the run is the result of the ideal percent between stride length and its frequency (COH, M. \& TOMAZIN, K. ,2005: 3) (FRYE, C. ,2000:35), Coh and others (2006) divided speed run to ( reaction time - acceleration speed, phase of maximum speed, phase of deceleration Phase, endurance speed) (COH, M.; TOMAZIN, K. \& STUHEC, S ,2006:103).

During the rapid development of standard scores of 100 meter run which has proved to the world the great scientific development, which led the researchers to study this development to stay on the causes of the gap between the national and international standard and search for the biomechanical analysis of the world championship of IAAF to determine the phases of 100 meter run, and detect the causes of the international progress compared with the local standard to develop kinematic efficiency of the peak 
deceleration speed phase and its impact on the 100 meter run of the players of the study sample.

The research problem is a serious trial to determine a specific training program for the development of the power of the local players to keep the levels of the maximum speeds to the longest distance in 100 meter run through the kinematic markers of 100 meter run.

\section{Aim of the study}

1- Kinematic Analysis of the segments of 100 meter run and the maximum deceleration speed phase of the $(70-80$ meters $)$ segment.

2- The effect of the proposed training program on the kinematic markers of 100 meter run and the maximum deceleration speed phase of the $(70-$ 80 meter) segment.

\section{Research Questions}

1- What are the main kinematic markers of the 100 meter run segments and the maximum deceleration speed phase of the (70 -80 meter) segment?
2- Is there a significant statistical difference between pre-posttests in the most important kinematic markers of 100 meter run and the maximum deceleration speed phase of the (70

-80 meter) segment?

\section{Glossary used in the study}

\section{Maximum deceleration speed phase:}

Is a phase which begins from the end of maximum peak speed of the player till the end of 100 meter run.

\section{Study procedures}

\section{Research method}

The researchers used the experimental method of pre-post measurement of one group by using the mechanical analysis Simi Motion program.

\section{Research sample}

The research sample was detected using random method of (3) players of Egyptian National track and field team of 100 meter run, of the 1st degree, each player tried (2) trials of 100 meter run, so making the real study sample (6) trials .

Table (1)

Characteristic features of the sample

\begin{tabular}{|c|c|c|c|c|c|c|c|c|}
\hline No & Player name & Club & $\begin{array}{c}\text { Length } \\
(\mathrm{met})\end{array}$ & $\begin{array}{c}\text { Weight } \\
(\mathrm{kg})\end{array}$ & $\begin{array}{c}\text { Age } \\
(\mathrm{yr})\end{array}$ & $\begin{array}{c}\text { Train } \\
\text { age }(\mathrm{yr})\end{array}$ & $\begin{array}{c}\text { Personal } \\
\text { score }(\mathrm{met})\end{array}$ & $\begin{array}{c}\text { BMI } \\
(\mathrm{kg} / \mathrm{m} 2)\end{array}$ \\
\hline 1 & $\begin{array}{c}\text { Ahmed A } \\
\text { Mohamed }\end{array}$ & Contractors Zagazig & 1.70 & 67 & 22 & 7 & 10.64 & 23.183 \\
\hline 2 & Mohamed A Abbas & Contractors Zagazig & 1.71 & 68 & 25 & 12 & 10.71 & 23.288 \\
\hline 3 & $\begin{array}{c}\text { Samir F. } \\
\text { Samir }\end{array}$ & Contractors Zagazig & 1.75 & 69 & 20 & 5 & 10.94 & 22.550 \\
\hline
\end{tabular}

\section{Means of data collection:}

1 - Tools and equipment's used in the study :

- Balance weight

- Restameter

- Stop watch to measure the time of 100 meters race.

- Begin cubes

- Treadmill cybex

- Rubber bands - rods - tires - Umbrellas

2- Tools of Movement analysis :
- Simi Motion computer and program unit

- 5 of Calibration box $1 \mathrm{mx} 1 \mathrm{~m}$.

- 5 Video camera 30 cadre/s. "Sony HD"

- 5 Triholder and Data show

\section{Pilot Study:}

Pilot study was achieved on the study sample, on Saturday $11 / 3 / 2017$ as a preparation to photograph 100 meter run, the distance of the 100 meter run racing was distributed to 10 equal segments, calibration box was set at the beginning of the distance of the selected section for each camera which was 20 meters, It is the distance to see the camera, the camera was installed vertically on the player, 15 meter from (track 4) and 1. 10 meter height for a 
distance 15 meter far away, and the photograph place occurred at zagazig university stadium, This study resulted in determining the location of the cameras and the calibration box as well as the stage of decreasing the maximum speed in the section of (70-80 meters).

Figure (1)

Camera places and positions

Decreasing the maximum speed stage

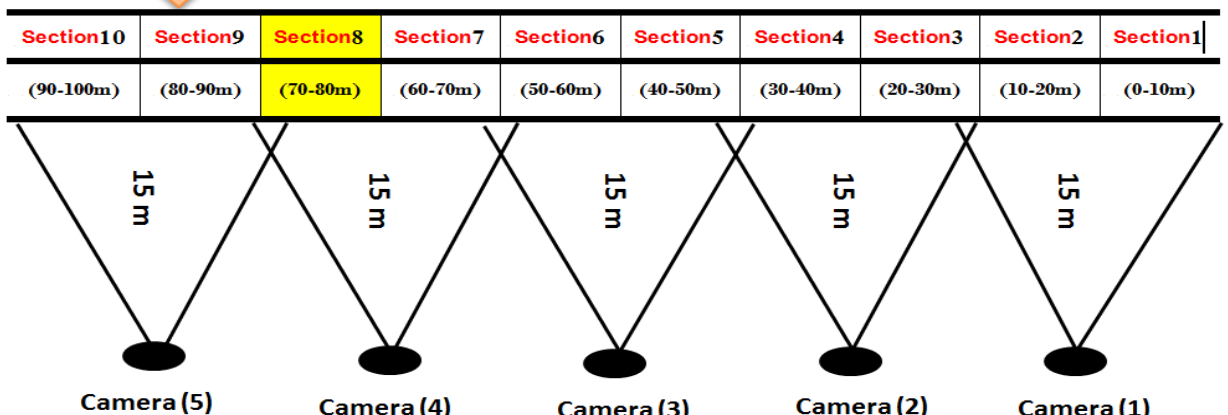

\section{Pre measurement:}

The pre measurement was achieved by the researchers by (2) legal trials for each player for 100 meter run racing the whole trials were (6), at Tuesday the 14/3/2017 in Zagazig university stadium .

\section{The training program:}

The determination of the training program was for 8 executive weeks, 3 training units per week, beginning from Sunday 26/3/2017 to Thursday 18/5/2017.

The aim of the training program was to increase the stride length and increase the frequencies of the stride of 100 meter run racing in general and deceleration speed phase in particular.

\section{Basis and rationing of the training program:}

- Taking care of the graduation and wave of the load.

- Using motor flexibility exercises and pelvis stability.

- Putting high altitude training exercise for a distance not exceeding 50 meter.

- Putting the running exercises of slope with a grade $(2: 3 \%)$, on condition that the grade of the trunk bent not exceeding $15 \%$ and for 100 meter distance.

- Preservation of the maximal speed of the run on slopes for a distance not exceeding (30-40 meter).
- Running in the presence of winds, running with the use of rubber band running on treadmill.

- Good warming up and stretching before training, and run (6-8) training trials before acceleration of the tread mill to the highest speeds.

- Running on (sand - tough sur face, running while holding load, running on water, pulling, tires or umbrellas.

- It is not allowed that the player exceeding (2 training units) of maximal loads successively.

- Positive rest

\section{Training loads of the training program:}

The training loads were from $35: 105 \%$ of maximum performance, Cissik (2005) reported that the runner should not exceed a speed more than $106-110 \%$ of maximum speed to avoid any problem in run mechanism (CISSIK,J.M ,2005 : 18).

\section{- Load volumes}

The training unit duration is (120 - 150 minute), frequency numbers (2-10), and the sets numbers (1-4) sets.

\section{- Rest intervals:}

Rest intervals positively

\section{Post measurement}

post measurement was determined by performing (2) legal trials by each player, of 100 meter run racing reaching a sum of (6) trials ( $3 \times 2)$, the Saturday 20/5/2017 at Zagazig university stadium track,And subjected to mechanical 
analysis to determine (segment speed stride numbers stride length and its frequency) and the frequency rate of steps (number of steps / average time)،and mechanical analysis of the phase section decreasing the maximum speed per meter detailed.

\section{Results:}

Table (2)

The kinematic variables of 100 meter run segments

\begin{tabular}{|c|c|c|c|c|c|c|c|c|c|c|c|}
\hline \multicolumn{2}{|c|}{$\begin{array}{l}100 \text { meter } \\
\text { segments }\end{array}$} & \multicolumn{2}{|c|}{$\begin{array}{c}\text { Segment } \\
\text { Duration (s.) }\end{array}$} & \multicolumn{2}{|c|}{$\begin{array}{c}\text { Segment } \\
\text { speed }(\mathrm{m} / \mathrm{s})\end{array}$} & \multicolumn{2}{|c|}{$\begin{array}{c}\text { No of } \\
\text { strides (No) }\end{array}$} & \multicolumn{2}{|c|}{$\begin{array}{c}\text { Stride } \\
\text { Length (Meter.) }\end{array}$} & \multicolumn{2}{|c|}{$\begin{array}{c}\text { Stride Frequency } \\
\text { (Stride/s) }\end{array}$} \\
\hline & & B & A & B & A & B & A & B & A & B & A \\
\hline \multirow{10}{*}{ 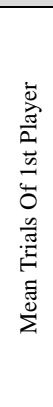 } & $10-0$ & 2.22 & 2.20 & 4.50 & 4.54 & 8.05 & 7.80 & 1.24 & 1.28 & 3.62 & 3.54 \\
\hline & $20-10$ & 1.19 & 1.16 & 8.37 & 8.59 & 4.64 & 4.49 & 2.16 & 2.23 & 3.88 & 3.86 \\
\hline & $30-20$ & 1.10 & 1.06 & 9.09 & 9.43 & 4.52 & 4.38 & 2.21 & 2.28 & 4.11 & 4.13 \\
\hline & $40-30$ & 1.00 & 0.99 & 9.99 & 10.09 & 4.31 & 4.18 & 2.32 & 2.39 & 4.30 & 4.21 \\
\hline & $50-40$ & 0.99 & 0.97 & 10.12 & 10.33 & 4.41 & 4.28 & 2.27 & 2.34 & 4.47 & 4.42 \\
\hline & $60-50$ & 0.96 & 0.95 & 10.37 & 10.58 & 4.19 & 4.06 & 2.38 & 2.46 & 4.35 & 4.30 \\
\hline & $70-60$ & 0.95 & 0.93 & 10.52 & 10.71 & 3.97 & 3.85 & 2.52 & 2.60 & 4.18 & 4.12 \\
\hline & $80-70$ & 0.96 & 0.94 & 10.38 & 10.60 & 3.97 & 3.64 & 2.52 & 2.75 & 4.12 & 3.85 \\
\hline & $90-80$ & 0.97 & 0.95 & 10.34 & 10.58 & 3.86 & 3.85 & 2.59 & 2.60 & 3.99 & 4.07 \\
\hline & $100-90$ & 1.11 & 0.96 & 9.05 & 10.45 & 3.75 & 3.74 & 2.66 & 2.68 & 3.39 & 3.91 \\
\hline \multirow{10}{*}{ 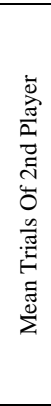 } & $10-0$ & 2.31 & 2.21 & 4.32 & 4.52 & 8.13 & 7.84 & 1.23 & 1.27 & 3.52 & 3.54 \\
\hline & $20-10$ & 1.21 & 1.17 & 8.26 & 8.54 & 4.68 & 4.52 & 2.14 & 2.21 & 3.87 & 3.86 \\
\hline & $30-20$ & 1.10 & 1.07 & 9.12 & 9.38 & 4.57 & 4.40 & 2.19 & 2.27 & 4.17 & 4.13 \\
\hline & 40-30 & 1.00 & 1.00 & 10.03 & 10.03 & 4.35 & 4.20 & 2.30 & 2.38 & 4.37 & 4.21 \\
\hline & $50-40$ & 0.99 & 0.97 & 10.07 & 10.27 & 4.46 & 4.30 & 2.24 & 2.33 & 4.49 & 4.42 \\
\hline & $60-50$ & 0.97 & 0.95 & 10.31 & 10.52 & 4.24 & 4.09 & 2.36 & 2.45 & 4.37 & 4.30 \\
\hline & $70-60$ & 0.94 & 0.94 & 10.65 & 10.65 & 4.01 & 3.87 & 2.50 & 2.59 & 4.27 & 4.12 \\
\hline & $80-70$ & 0.97 & 0.95 & 10.29 & 10.54 & 3.90 & 3.66 & 2.57 & 2.74 & 4.01 & 3.85 \\
\hline & $90-80$ & 0.98 & 0.95 & 10.20 & 10.52 & 4.01 & 3.87 & 2.50 & 2.59 & 4.09 & 4.07 \\
\hline & $100-90$ & 1.10 & 0.96 & 9.10 & 10.40 & 3.79 & 3.76 & 2.64 & 2.66 & 3.45 & 3.91 \\
\hline \multirow{10}{*}{ 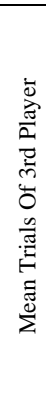 } & $10-0$ & 2.30 & 2.27 & 4.36 & 4.41 & 8.31 & 8.03 & 1.20 & 1.25 & 3.62 & 3.54 \\
\hline & $20-10$ & 1.22 & 1.20 & 8.21 & 8.35 & 4.78 & 4.62 & 2.09 & 2.16 & 3.93 & 3.86 \\
\hline & $30-20$ & 1.12 & 1.09 & 8.92 & 9.17 & 4.67 & 4.51 & 2.14 & 2.22 & 4.16 & 4.13 \\
\hline & $40-30$ & 1.08 & 1.02 & 9.26 & 9.81 & 4.45 & 4.30 & 2.25 & 2.33 & 4.12 & 4.21 \\
\hline & $50-40$ & 1.00 & 1.00 & 10.01 & 10.04 & 4.55 & 4.40 & 2.20 & 2.27 & 4.56 & 4.42 \\
\hline & $60-50$ & 0.99 & 0.97 & 10.08 & 10.28 & 4.33 & 4.18 & 2.31 & 2.39 & 4.36 & 4.30 \\
\hline & $70-60$ & 0.99 & 0.96 & 10.10 & 10.41 & 4.10 & 3.96 & 2.44 & 2.53 & 4.13 & 4.12 \\
\hline & $80-70$ & 0.99 & 0.97 & 10.08 & 10.30 & 4.10 & 3.74 & 2.44 & 2.67 & 4.13 & 3.85 \\
\hline & $90-80$ & 1.02 & 0.97 & 9.76 & 10.28 & 3.98 & 3.96 & 2.51 & 2.53 & 3.89 & 4.07 \\
\hline & $100-90$ & 1.11 & 0.98 & 9.00 & 10.16 & 3.87 & 3.85 & 2.58 & 2.60 & 3.49 & 3.91 \\
\hline
\end{tabular}

Table (2) reveals the means of the (3) players of pre-post measurements of kinematic variables of 100 meter run segments. 
Table (3)

Statistical analysis of the kinematic variables of 100 meter run $(n=6)$

\begin{tabular}{|c|c|c|c|c|c|c|c|c|c|c|}
\hline \multirow{2}{*}{$\begin{array}{c}\text { Kinematic } \\
\text { variables }\end{array}$} & \multicolumn{2}{|c|}{$\begin{array}{c}100 \text { M.Run } \\
\text { Duration(s.) }\end{array}$} & \multicolumn{2}{c|}{$\begin{array}{c}100 \mathrm{M} \text {. Run } \\
\text { speed(m/s) }\end{array}$} & \multicolumn{2}{|c|}{$\begin{array}{c}\text { Strides } \\
\text { ( No) }\end{array}$} & \multicolumn{2}{|c|}{$\begin{array}{c}\text { Stride } \\
\text { Length (Meter.) }\end{array}$} & \multicolumn{2}{c|}{$\begin{array}{c}\text { Stride Frequency } \\
\text { (Stride/s) }\end{array}$} \\
\cline { 2 - 12 } & B & A & B & A & B & A & B & A & B \\
\hline $\begin{array}{c}\text { Mean Trials } \\
\text { of 1st Player }\end{array}$ & 11.46 & 11.11 & 9.27 & 9.59 & 45.67 & 44.25 & 2.29 & 2.36 & 4.04 & 4.04 \\
\hline $\begin{array}{c}\text { Mean Trials } \\
\text { of 2nd Player }\end{array}$ & 11.57 & 11.17 & 9.24 & 9.54 & 46.13 & 44.49 & 2.27 & 2.35 & 4.06 & 4.04 \\
\hline $\begin{array}{c}\text { Mean Trials } \\
\text { of 3rd Player }\end{array}$ & 11.82 & 11.43 & 8.98 & 9.32 & 47.14 & 45.53 & 2.22 & 2.30 & 4.04 & 4.04 \\
\hline $\begin{array}{c}\text { Mean trials } \\
\text { of players }\end{array}$ & 11.62 & 11.24 & 9.16 & 9.48 & 46.31 & 44.76 & 2.26 & 2.33 & 4.05 & 4.04 \\
\hline
\end{tabular}

Table (3) reveals the mean trials of the (3) players of pre-post measurements of the kinematic variables of 100 meter run.

Table (4)

Statistical differences of pre-post measurements of kinematic variables of the deceleration speed (70 - 80 meter) of 100 meter run $(n=6)$

\begin{tabular}{|c|c|c|c|c|c|c|c|c|}
\hline \multirow{2}{*}{$\begin{array}{c}\text { Kinematic variables } \\
\text { segment } \\
(70-80 \mathrm{met})\end{array}$} & \multirow[b]{2}{*}{$\begin{array}{c}\text { Measure } \\
\text { unit }\end{array}$} & \multirow[b]{2}{*}{ mean pre test } & \multirow[b]{2}{*}{$\begin{array}{l}\text { mean post } \\
\text { test }\end{array}$} & \multicolumn{2}{|c|}{ Mean order } & \multirow{2}{*}{$\begin{array}{l}\text { Wilcoxon } \\
\text { test } \\
\text { Z Value }\end{array}$} & \multirow[b]{2}{*}{ Sig p.value } & \multirow[b]{2}{*}{$\begin{array}{c}\% \\
\text { change }\end{array}$} \\
\hline & & & & $\begin{array}{c}(-) \\
\text { signal }\end{array}$ & $\begin{array}{c}(+) \\
\text { signal }\end{array}$ & & & \\
\hline Segment duration & S. & 0.98 & 0.95 & 3.50 & 0.00 & 2.45 & 0.014 & 2.22 \\
\hline Segment speed & $\mathrm{m} / \mathrm{s}$ & 10.25 & 10.48 & 0.00 & 3.50 & 2.27 & 0.023 & 2.27 \\
\hline No. of strides & No. & 3.99 & 3.68 & 3.50 & 0.00 & 2.22 & 0.026 & 7.76 \\
\hline Stride length & Meter & 2.51 & 2.72 & 0.00 & 3.50 & 2.27 & 0.023 & 8.38 \\
\hline Stride Frequency & Stride/s & 4.08 & 3.85 & 0.00 & 3.50 & 2.22 & 0.026 & 5.66 \\
\hline
\end{tabular}

\section{* Sig p.value $<0.05$}

Table (5)

Statistical differences of pre-post measurement of kinematic variables of 100 meter run $(n=6)$

\begin{tabular}{|c|c|c|c|c|c|c|c|c|}
\hline \multirow{2}{*}{$\begin{array}{c}\text { Kinematic } \\
\text { variables } 100 \\
\text { meter run }\end{array}$} & \multirow[b]{2}{*}{$\begin{array}{c}\text { Measure } \\
\text { unit }\end{array}$} & \multirow[b]{2}{*}{ mean pre test } & \multirow[b]{2}{*}{$\begin{array}{c}\text { mean post } \\
\text { test }\end{array}$} & \multicolumn{2}{|c|}{ Mean order } & \multirow{2}{*}{$\begin{array}{c}\text { Wilcoxon } \\
\text { test } \\
\text { Z Value }\end{array}$} & \multirow[b]{2}{*}{$\begin{array}{c}\text { Sig } \\
\text { p.value }\end{array}$} & \multirow[b]{2}{*}{$\begin{array}{c}\% \\
\text { change }\end{array}$} \\
\hline & & & & $\begin{array}{c}(-) \\
\text { signal }\end{array}$ & $\begin{array}{c}(+) \\
\text { signal }\end{array}$ & & & \\
\hline $\begin{array}{c}\text { Duration } 100 \\
\text { meter run }\end{array}$ & S. & 11.62 & 11.24 & 3.50 & 0.00 & 2.22 & 0.026 & 3.27 \\
\hline $\begin{array}{l}\text { Speed } 100 \\
\text { meter run }\end{array}$ & $\mathrm{m} / \mathrm{s}$ & 9.16 & 9.48 & 0.00 & 3.50 & 2.22 & 0.026 & 3.51 \\
\hline No. of strides & No. & 46.31 & 44.76 & 3.50 & 0.00 & 2.22 & 0.026 & 3.35 \\
\hline Stride length & Meter & 2.26 & 2.33 & 0.00 & 3.50 & 2.22 & 0.026 & 3.47 \\
\hline Stride Frequency & No. & 4.05 & 4.04 & 3.50 & 3.50 & 0.74 & 0.459 & 0.13 \\
\hline
\end{tabular}

* Sig p.value $<0.05$

\section{Results Discussion:}

Table (5) indicates that there are significant changes $\mathrm{p}<$ 0.05 of all kinematic variables of 100 meter run except stride frequency, and the significant differences were for the sake of the post measurement variables except stride frequency.

Table(1)indicates an elevation of curve speed of the segments of 100 meter run of pre measurement, the least value of speed variable of the first segment "race start"'(0:10 meters) of the three players $(4.5 \mathrm{~m} / \mathrm{s})(4.32 \mathrm{~m} / \mathrm{s})$ $(4.36 \mathrm{~m} / \mathrm{s})$ Reaching the highest speed values of the segment $(60-70$ meters $)$ which is the maximal speed stage which reach the values of the three players $(10.52$ $\mathrm{m} / \mathrm{s})(10.65 \mathrm{~m} / \mathrm{s})(10.10 \mathrm{~m} / \mathrm{s})$ and these values are related to the stride length of the 100 meter run phase generally and intra different segments specifically, and the stride length of the first segment "race start" was between (1.20: 
1.24 meter) for the three players, whereas reach a higher value in case of (60-70 meter) segment, which is related to the highest maximal speed values of 100 meter run (2.44: 2.52 meter).

The researchers explain through kinematic analysis of the 100 meter run segments, that the highest average of the maximal speed was in segment $(60-70$ meter $)$, them the maximal speed reduced in case $(70-80$ meter) segment, which is example of reduced speed phase, And were subjected to the mechanical analysis for each meter within that section to determine the actual distance where the speed curve begins to decline, this is in accordance with the results of table (1) and fig. (2) and the values of speed of the segments $(60-70$ meter $)$ and $(70-80$ meter $)$ of the pre measurements of the three players were $(10.52-10.38$ $\mathrm{m} / \mathrm{s}),(10.65-10,25 \mathrm{~m} / \mathrm{s}),(10.10-10.80 \mathrm{~m} / \mathrm{s})$, and the segment $(70-80$ meter $)$ is example of the beginning of reduced maximal speed, which is related to the player trial to preserve the maximal speed to the longest distance till the race finish or end.

Figure (2)

Indicates the maximal Speed reduction stage of 100 meter run

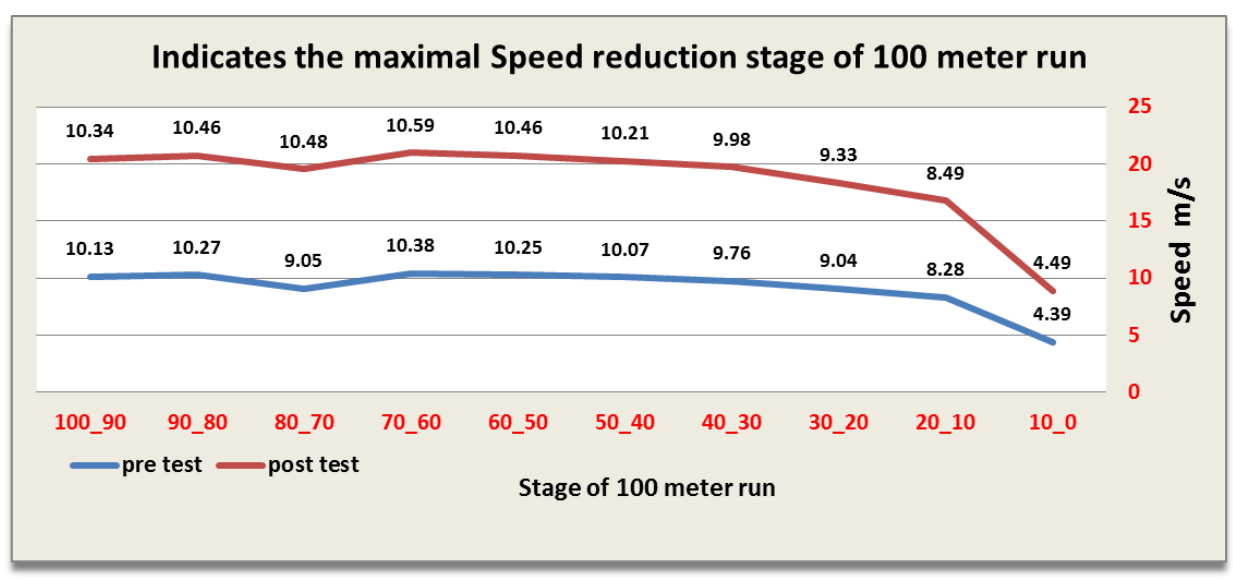

Table (4) indicated the results of pre-post kinematic variables of the maximal speed reduction phase of the $(70$ -80 meter) segment, and the $\mathrm{p}$ values were less than 0.05 , results were statistically significant between the two measurements, for the favor of post measurement in variables of (segment time (duration), segment speed stride numbers stride length and its frequency) and the percent change in case of segment speed $(2.27 \%)$, and the average value of pre measurement $(10.24 \mathrm{~m} / \mathrm{s})$ and for post measurement $(10.48 \mathrm{~m} / \mathrm{s})$. This means that the three players have increased their average seed in the maximal speed reduction phase this help to preserve the maximal speed values to the longest distance of 100 race run indicated in Fig. (3)

Figure (3)

Beginning of maximal speed Reduction phase of the ( 70 - 80 meter) segment

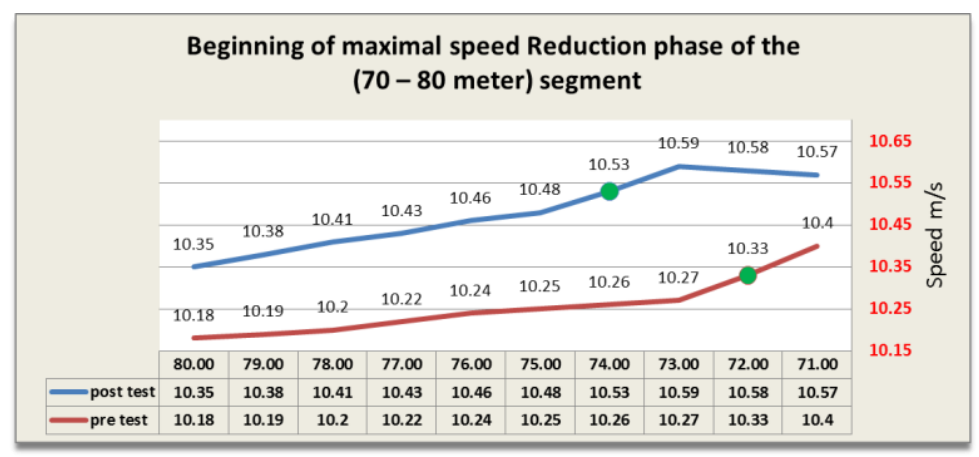


Mehmet kale (2016), Krzysztof MacKala et al (2015) and Jurgen Schiffer (2011) reported that the progress of the player due to the speed development program, is in line with the importance of selection of suitable exercises and training, because the more the elevation of the physical performance of the players, the less the available exercises that develop the score level, in this case the direction of the training program changes from general preparation to a more specific preparation which enable the player to develop his score - level .

The researchers are in accordance with khaled Attiate (2015), wadiea Morsi (2013), that the positive effect of the proposed training program with kinematic analysis of the 100 meter run segment and the use of the specific training exercises (resistant-helper) and references with the scientific basis of the development of the length and frequency of the stride, all together induce this positive effect.

The beginning of the reduction of the average maximal speed of Players is in distance (72 meter) of the pre measurement which was improved in post measurement to (74 meter) due to increased average maximal speed and its preservation and does not fall early to speed curve, this will be positively reflected on the segment duration (70-80 meter) their time reach in pre and post measurement $(0.98$ $\mathrm{S}$ and $0.95 \mathrm{~S}$.), and this progress was positively reflected on the stride length and its frequency, as the stride length of pre-post segment $(2.51-2.72$ meter $)$ and the average frequency of the pre-post measurements $(4.08-3.85$ stride/S.), the progress of the segment stride length was reflected on the stride numbers which reach in pre and post measurements $(3.99-3.68$ stride $)$.

Table (5) indicated that the kinematic variables of 100 meter run was improved significantly due to the development of maximal speed curve, the highest percent change was $(3.51 \%)$ between the pre and post measurements in average speed of 100 meter race run and their values reach $(9.16-9.48 \mathrm{~m} / \mathrm{s})$, this was related with the percent improving change of the stride length which reach $(3.47 \%)$ between pre and post measurements which values reach $(2.26-2.36$ meter $)$.

Also, Table (5) shows the positive relationship between speed and stride length variables of 100 meter race run and the frequency of strides as the average stride numbers of 100 meter race run of the pre measurement was (46.31 stride) compared with the post measurement (44.76 stride)

There are non-significant change in frequency of strides for the sake of the post measurement as the results were (4.05 - 4.04 stride/s) of pre and post measurements. The researchers explained the result that the average stride frequency of 100 meter race run does not significantly change, but the average change of the stride frequency in maximal speed reduction phase of the $(70-80$ meter $)$ segment was due to the improvement of the length and stride speed of the segment as indicated in table (4).

The researchers come to the conclusion through the kinematic analysis of the time of 100 meter race run in pre measurement (11.62 S.) and post measurement (11.24 S.) , that the progress in time was due to the development induced in maximal speed reduction phase in $(70-80$ meter) segment, through the positive effect of the proposed training program on the kinematic variables of the race and maximal speed reduction phase also due to the preservation of maximal speed to the longest distance of the race and the delay of the fall of average maximal speed till the end of the race.

\section{Conclusions and Recommendations:}

\section{First - Conclusions}

1 - Find the main kinematic variables of the segment and 100 meter race run in general and the phase of maximal speed reduction of (70 -80 meter) segment .

2- The stride length was the most efficient cause in the development of the 100 meter race run time in general and the improvement in run speed in the segment of the phase of maximal speed reduction in particular.

3- The development of the phase of maximal speed reduction depend on the player ability to preserve the maximal speed as long distance as he can, which was improved from (72 meter) to (74 meter) .

\section{2nd: Recommendations:}

1- The kinematic variables of the segments of 100 meter race run must be used as a guide to be applied and used in the process of training and correct the errors.

2- To concentrate on improving the maximal speed during the phase of maximal speed reduction due to its importance in development of race time.

3- To be guided by the specific training exercises (Resistance-helper) to improve the stride length and frequency.

\section{References}

1- CISSIK,J.M (2005):Means and methods of speed training :Part II. NSCA Journal, 27(1), P 18-25. 
2- COH, M. \& TOMAZIN, K. (2005): Biomechanical characteristics of female sprinters during the acceleration phase and maximum speed phase. Modern Athlete and Coach, 43(4), P 3-9.

3- COH, M.; TOMAZIN, K. \& STUHEC, S (2006): The biomechanical models of the sprint start and block acceleration. Facta Universities: Series Physical Education and Sport, 4 (2), P103-114.

4- FRYE, C. (2000): 100 and 200 meters. In: J. L. Rogers (Ed.), USA track \& field coaching manual, Champaign, Ill, Human Kinetics. P 35-50.

5- KALE1, M. \& ACIKADA, C. (2016):Effects of stride length and frequency training on acceleration kinematic, and jumping performances, Sport Science Review, 25(3), PP $243-260$.

6- Khaled M.A (2015) : Kinematic performance of strides of males and females short distance runners, Educational sciences , 42 (2), (In Arabic language )
7- Maćkała, K., Fostiak, M. \& Kowalski, K. (2015):Selected Determinants of Acceleration in the $100 \mathrm{~m}$ Sprint, Journal of Human Kinetics, 45(1), PP135-148.

8- Schiffer, J. (2011): Training to Overcome the Speed Plateau, The International Association of Athletics Federations NEW STUDIES IN ATHLETICS, 26(1), PP $7-16$.

9- Talha, H. (2014) : Alphabetic of movement sciences in their fields and applications in physiology and anatomy update book center, Cairo, 17 , (In Arabic language )

10- The International Association of Athletics Federations (2011): NEW STUDIES IN ATHLETICS “IAAF"- Focus on the Sprints, 26 (1), P3.

11- Wadiea; MM (2013) : The effect of strength loads changes on some biomechanical variables of stride run PHD, Fac. Fac. Of physical Education, El Mansoura university, (In Arabic language). 